\title{
Green certificate trading
}

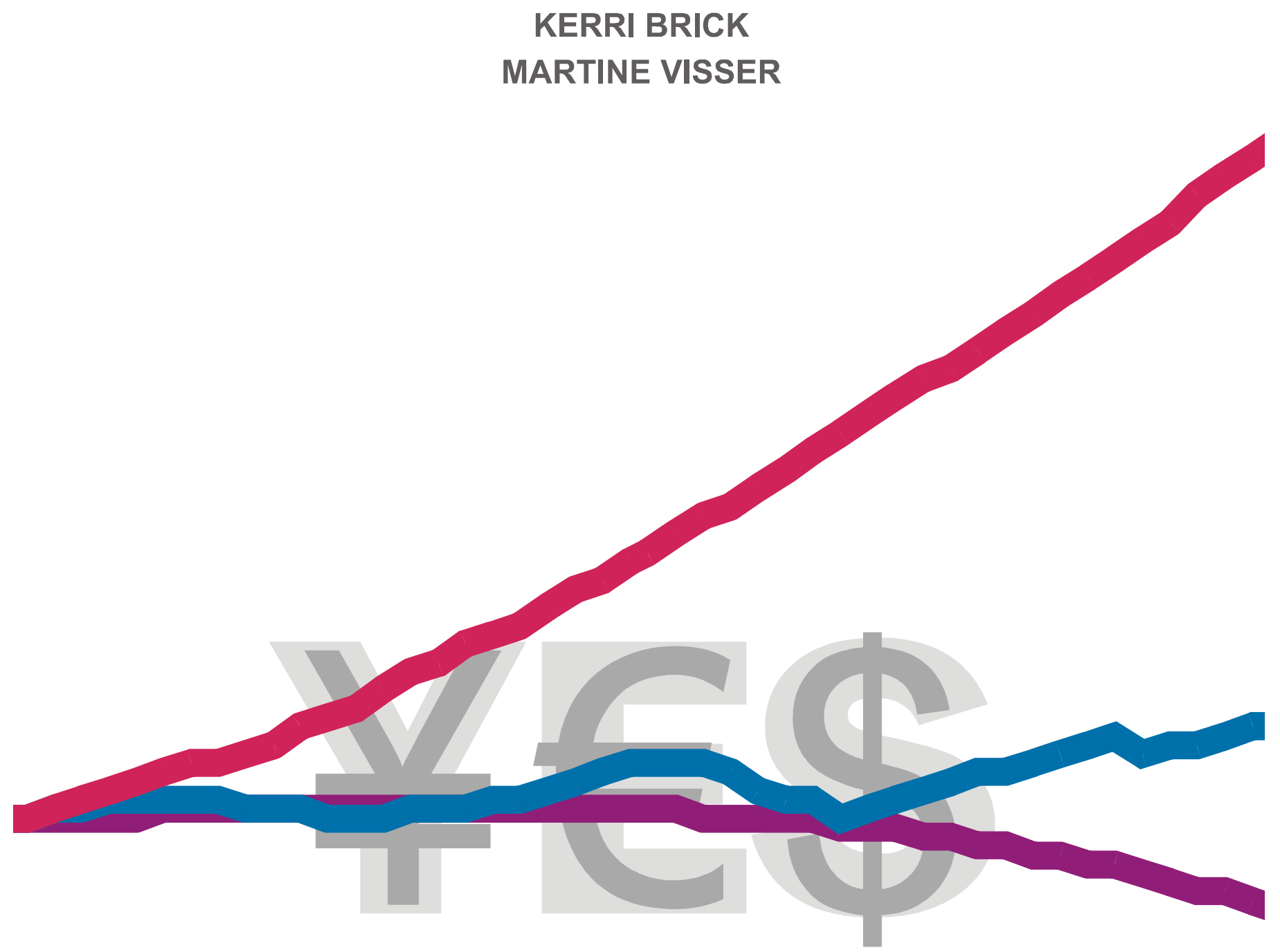

Energy Research Centre

ENIVERSITY OF CAPE TOWN

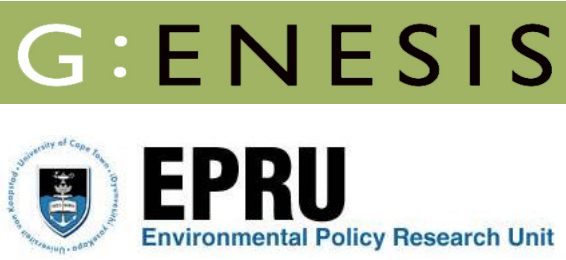




\section{Green certificate trading}

\section{KERRI BRICK}

MARTINE VISSER

Energy Research Centre

UNIVERSITY OF CAPE TOWN

\section{G:ENESIS \\ (a) EPRU \\ Environmental Policy Research Unit}




\section{Acknowledgements}

These reports are the result of collaboration between the Energy Research Centre (ERC), Environmental Policy Research Unit (EPRU) and Genesis Analytics. ERC and EPRU are both research units at the University of Cape Town. The research by Genesis Analytics was commissioned by ERC, drawing on NRF funding which is gratefully acknowledged. The individual reports may also appear in other report series. 


\section{Contents}

1. Introduction: international and domestic context 1

2. Policy instruments for the promotion of renewable energy 2

3. Green certificate trading 4

3.1 Life cycle of a TREC 5

3.2 Elements of a TREC system 5

3.3 Green certificate trading in South Africa 6

$\begin{array}{ll}3.4 \text { Motivation for a national TREC system } & 6\end{array}$

4. International implementation of renewable energy support mechanisms

$\begin{array}{lll}4.1 & \text { Europe } & 7\end{array}$

$\begin{array}{lll}\text { 4.1.1 } & \text { EU-15 member states } & 7\end{array}$

4.1.2 The Renewable Energy Certificate System 8

4.2 United States 8

$\begin{array}{lll}4.3 & \text { Australia } & 9\end{array}$

5. Basic design issues and concepts: lessons from the international experience; framework for a national TGC scheme

6. Comparison of feed-in tariff and quota obligation combined with TGCs: lessons from $\begin{array}{lr}\text { international experience } & 12\end{array}$

$\begin{array}{lll}6.1 & \text { Feed-in tariffs } & 12\end{array}$

$\begin{array}{ll}\text { 6.2 Quota obligations based on tradable green certificates } & 13\end{array}$

7. Interaction between emissions trading and renewable energy promotion 13

$\begin{array}{ll}\text { References } & 14\end{array}$ 


\section{Introduction: international and domestic context}

Strong action is needed to reduce global greenhouse gas (GHG) emissions and reverse the trend towards higher global temperatures (Stern Review, 2007). Given the threat to the climate from fossil fuels, a focus on clean energy and energy efficiency is growing (DEAT, 2008). Increasing the share of renewable energy in terms of the national energy mix is rising to the top of political agendas worldwide.

The Intergovernmental Negotiating Committee for a Framework Convention on Climate Change drafted the United Nations Framework Convention on Climate Change (UNFCCC), which was opened for signature in 1992. 'The primary objective of the UNFCCC is to achieve stabilisation of the concentrations of GHG in the atmosphere at a level that would prevent dangerous anthropogenic interference with the climate system' (UNFCCC, 1992). As South Africa ratified the UNFCCC in 1997, the country is entitled to apply for financial assistance from the Global Environmental Facility for climate change related activities.

The Kyoto Protocol, ${ }^{1}$ a legal instrument under the framework of the Convention, sets binding targets under which industrialised (Annex I) countries must reduce greenhouse gas emissions by an average of five percent against 1990 levels over the period 2008-2012 (UNFCCC, 1997). The Kyoto Protocol is the first and only binding international agreement to set targets for the reduction of greenhouse gas emissions (Fakir and Nicol, 2008).

In March 2002, South Africa acceded to the Protocol. While the Protocol does not commit nonAnnex I (developing) economies such as South Africa to quantified emission reduction targets over the period 2008-2012, there is potential for emission reduction through the Clean Development Mechanism (CDM) which promotes emission reductions between non-Annex I countries and Annex I countries. The CDM facilitates Annex I investment in emission-reducing projects in non-Annex I economies. In this way, Annex I countries are able to obtain carbon credits to enable them to meet their emissions reduction targets. As such, the CDM supports sustainable development with respect to GHG emissions in developing countries while helping Annex I countries to comply with their Kyoto Protocol commitments and reducing the overall level of GHG emissions. ${ }^{2}$ (DME, 2003; Fakir and Nicol, 2008)

South Africa is very dependent on fossil fuels as a primary energy source. Specifically, around 90 percent of energy is derived from low cost coal (DEAT, 2008). Furthermore, 93 percent of electricity generation is based on coal (Winkler, 2005). South Africa is ranked $19^{\text {th }}$ in terms of world emissions (based on absolute totals for six $\mathrm{GHGs}^{3}$ in 2000) contributing 1.1 percent of the global emissions total, and is ranked $13^{\text {th }}$ in terms of the carbon intensity of electricity production (CAIT, 2009). In the 2003 White Paper on Renewable Energy, while recognizing South Africa's dependence on fossil fuels to meet energy requirements, the state acknowledged the growing need for South Africa to become a responsible 'global neighbour', amid mounting concerns about global climate change (DME, 2003).

In this context, the 2003 White Paper on Renewable Energy sets out government's vision for promoting renewable energy in South Africa:

Government's long-term goal is the establishment of a renewable energy industry producing modern energy carriers that will offer in future years a sustainable, fully non-subsidised alternative to fossil fuels. The proportion of final energy consumption currently provided by renewable energy has come about largely as a result of poverty (e.g.

1 The Kyoto Protocol was adopted on 11 December 1997 and entered into force in February 2005 (UNFCCC, 1997)

2 The current scenario of no quantified mitigation commitments is likely to change by then end of 2009. COP-15 in Copenhagen are expected to agree on 'measurable, reportable and verifiable' mitigation actions for developing countries, supported and enabled by technology and finance from developed countries.

3 CO2, CH4, N20, PFCs, HFCs and SF6 (CAIT, 2009) 
fuelwood and animal waste used for cooking and heating). To get started on a deliberate path towards this goal, the Government's medium-term (10-year) target is: 10 000 GWh renewable energy contribution to final energy consumption by 2013, to be produced mainly from biomass, wind, solar and small-scale hydro... This is approximately $4 \%$ (1667 MW) of the projected electricity demand for 2013 (41539 MW). (DME, 2003: ix)

This paper proceeds as follows: Section 2 briefly outlines the policy instruments available for the promotion of renewable energy sources, while section 3 discusses green certificate trading in more detail, including the green certificate market in South Africa at present. Section 4 describes the international implementation of renewable energy support mechanisms. The lessons learnt from this experience in terms of design suggestions for the development of a South African TREC framework are detailed in Section 5. Also from international experience, Section 6 provides a comparison of a feed-in tariff scheme and a quota obligation system combined with tradable green certificates. Finally, the interaction between emission trading schemes and renewable energy promotion systems are outlined in Section 7.

\section{Policy instruments for the promotion of renewable energy}

While energy is critical to all aspects of South Africa's economic and social development, the way in which it is produced and used can contribute to environmental degradation, such as air pollution, and climate change. The 'polluter pays' principle states that the party responsible for such pollution must pay for the negative environmental impacts caused. There is an internalisation of external costs if the polluter pays adequately for any environmental damage caused. When external costs, such as air pollution, are not internalised, the market mechanism fails to secure an optimal allocation of resources. This is because the prices of goods with large external costs are understated when these external costs are not internalised. As such, these goods are over-consumed relative to the optimal level of consumption for the wellbeing of society. The internalisation of external costs is therefore a necessary pre-condition for the optimal allocation of resources. When these externalities are internalised, energy production technologies will be allocated by the market according to their social costs, and the price of goods (electricity) will reflect their true cost (Ragwitz et al, 2006).

The European Commission has evaluated the external costs of different energy systems. The Commission's ExternE project on external costs estimated that the cost of producing electricity from coal or oil in the European Union would double and the cost of producing electricity from gas would increase by 30 percent if external costs, in the form of damage to environment and health, were taken into account (Ragwitz et al, 2006).

Renewable energy sources decrease pollution, contribute to the achievement of the Kyoto Protocol climate change mitigation goals, allow countries to improve security of energy supply by reducing fossil fuel dependency and provide numerous socioeconomic opportunities such as investment, development and job creation. Yet, despite these many benefits, renewable energy competes with conventional electricity on an unequal playing field amid a failure to internalize the negative externalities associated with conventional energy production (as discussed above). Public support is thus needed to level the playing field and promote the market penetration of renewable energy sources (Gonzalez, 2007).

In many countries, particularly in Europe, the main policy instrument used to support renewable electricity ${ }^{4}$ deployment is the feed-in tariff. In this system, a premium price is paid for all qualifying renewable electricity delivered to the grid. Utilities are obliged to purchase this electricity at the set price - which is determined by the state. Given that the costs of generation differ across the spectrum of renewable energy technologies, the feed-in tariff usually differs by

4 'Renewable electricity' is used in this report as a short-hand for electricity generated from renewable energy sources. Electricity is an energy carrier, and not renewable or non-renewable in itself; it depends on the energy sources that is used to generate electricity. 
technology and is provided for a specified time period. The feed-in tariff may also decrease over time in line with reductions in the cost of renewable energy generation. Theoretically, by setting the price but not the quantity of electricity produced, it is not known in advance how much renewable energy will be generated amid the scheme. However, the stability of a set price given that the tariff is high enough - can result in sustained growth in renewable energy generation. Conversely, the main criticism of the scheme is that too high a price may result in excessive producer surplus at the expense of electricity consumers (Linden et al, 2005).

Feed-in tariffs are used in many EU-25 member states, as will be discussed later. This system has had success in the deployment of wind, biomass and solar energy in Germany, Denmark and Spain. It is noted that the main advantage of the system as evidenced in these countries is certainty around the duration of financial support - which ultimately reduces the risk of investment (Ragwitz et al, 2006).

The use of quota obligation schemes has gained in popularity in recent years. In a quota obligation system - also referred to as a renewable obligation, renewable portfolio standard (RPS) or renewable energy target - a minimum share of renewable electricity is imposed on producers, suppliers or consumers. The implementation of an obligation system typically involves a penalty for non-compliance to ensure that obligated parties meet their renewable energy purchase obligations. The obligation scheme is often (but not necessarily) combined with tradable green certificates to simplify the burden of verifying compliance with the obligation and to enable flexibility in achieving compliance. Quota obligations combined with green certificates are used in Belgium, Italy, Sweden, UK and Poland, while 25 states in the United States, and Washington DC, have mandatory RPS obligations - with most RPS programmes incorporating the use of tradable renewable energy certificates (TRECs) (Linden et al, 2005; Ragwitz et al, 2006). ${ }^{5}$

A third category of renewable energy promotion systems is the tender scheme. In such a system, renewable energy developers compete for access to power purchase agreements (and/or government administered funds) through a competitive, government administered bidding process. The tenders can be differentiated according to different renewable energy technologies. Contracts are awarded to the most competitive bids within each technology band. Electricity utilities are often obliged to buy the electricity at the winning-bid-price. Tendering schemes of this kind have been used in, amongst others, the UK, Ireland, France, the US and China (Linden et al, 2005).

Although bidding processes are cost efficient, given that they stimulate competition among renewable energy generators, they have been less successful in promoting renewable energy relative to feed-in tariffs. This is likely due to uncertainty in the market arising from the intermittency of the tenders or the complexities of the bidding procedures themselves. Furthermore, it is argued that the bidding procedure leads to unrealistically low bids - resulting in funds being committed to projects which do not come to fruition. (Linder et al, 2005)

Additional measures can be used in conjunction with the main instruments mentioned above to ensure that the objectives for specific renewable energy technologies are met: financial subsidies for renewable energy technologies as specific $\$ / \mathrm{kW}$ grants or grants specified as a percentage of total investment; tax incentives such as tax refunds for renewable electricity,

5 The following hypothetical example illustrates the dynamic of a quota obligation system: Assume the electricity market consistent of generators, suppliers and customers. Generators sell their electricity to suppliers who in turn sell it to customers. Assume that 6 percent of supplied electricity must be renewable. In this example, all electricity suppliers must prove to the authorities that they have met this obligation by producing TRECs at year-end - one certificate for each MegaWatt hour (MWh) of electricity sold. A supplier who sold $1000000 \mathrm{MWh}$ of electricity during the specified period would have a renewable obligation of $60000 \mathrm{MWh}$. If the supplier fails to meet this obligation, he or she will likely have to pay a fine for every MWh sold that was not renewable. If the supplier failed to supply any renewable electricity and the fine was R100, he would be fined R6 million. It thus becomes very expensive not to comply with the renewable energy target. (REF, 2008) 
energy tax exemption for renewable electricity, reduced VAT rates for renewable electricity and the exemption of renewable energy-related investments from income or corporate taxes. Green marketing systems in which a premium on electricity voluntarily paid by consumers is transferred to renewable energy generators to cover the additional generation costs associated with renewable energy (Linden et al, 2005). ${ }^{6}$

As evident from Table 1, policy instruments can be classified in terms of whether they are priceor quantity-based instruments.

Table 1: Classification of policy measures

Source: Held and Ragwitz (2006)

\begin{tabular}{|l|l|}
\hline \multicolumn{1}{|c|}{ Priced-based mechanisms } & \multicolumn{1}{c|}{ Quantity-based mechanisms } \\
\hline Feed-in tariff & Quota combined with TGC $^{7}$ \\
Fiscal incentives & Tender schemes \\
Investment grants & \\
\hline
\end{tabular}

\section{Green certificate trading}

TRECs - also known as renewable energy certificates (RECs), green certificates or green tags, represent the renewable value or greenness of electricity produced from renewable sources, and are used to simplify the burden of verifying compliance with renewable energy targets and provide flexibility in meeting the target (Linden et al, 2005). TRECS can be banked, traded or consumed (redeemed), and can be sold bundled with the underlying physical electricity or separately to it (Linden et al, 2005). According to Morthorst (2001), the idea behind this policy scheme is to use market forces to determine the additional payment to investors in renewable energy technologies. Therefore, the payments to renewable generators consist of two parts: first, the sale of electricity to energy utility Eskom by power purchase agreement and, secondly, the sale of green certificates. The generated electricity and the certificates are traded at separate markets - the financial certificate market and the physical electricity market. Obligated market actors are able to purchase green certificates from the financial certificate market to meet renewable energy obligations (GreenX Energy, 2008) (Morthorst, 2001). By providing a revenue stream for developers, green certificate trading theoretically stimulates investment in renewable energy projects and facilitates the expansion of the renewable energy generation industry (Mitchell and Anderson, 2000).

Under a renewable energy obligation system, demand for renewable electricity from obligated market participants fuels demand for TRECs. In practice, TRECs could be purchased by obligated market participants directly from registered producers or from brokers and other intermediaries. In order to verify compliance with the obligation, obligated market participants must hand over the requisite number of certificates to the monitoring authority (typically on an annual basis). In this context, green certificates act as an accounting instrument which verifies whether the obligation has been met (Linden et al, 2005).

TRECs are priced at the differential between the electricity tariff and the cost of new renewable energy generation. In practice, administration and marketing costs are included in the final TREC price. (GreenX Energy, 2008).

6 This system depends on the consumers' willingness to pay (WTP) for renewable electricity. The WTP differs from country to country and is influenced by factors such as environmental awareness (Linden et al, 2005).

7 As per the convention in the literature, a quota obligation scheme operated in conjunction with tradable green certificates is considered a quantity-based policy mechanism. However, we consider pure green certificate trading schemes (with no quota obligation) such as the Renewable Energy Certificate System operating in Europe to be a hybrid of price and quantity-based instruments. 
TREC systems can be either voluntary or mandatory. In a voluntary policy environment, green certificates are used to track and verify green energy supply. The procurement of green energy in this manner can be used in the reporting of environmental performance. Conversely, in mandatory markets, where producers or consumers are obligated to produce or consume specified quantities of renewable energy, TRECs provide a mechanism for the verification and monitoring of compliance with such obligations. Importantly, as TRECs can be used in both a voluntary or mandatory policy environment, the system provides a useful bridging mechanism between the two. (DME, 2007)

\subsection{Life cycle of a TREC}

The life cycle of a TREC consists of four stages, specifically: registration of the generating device, issuing, trading and redemption of the certificate. These four stages are briefly discussed below.

Accreditation/registration: Renewable energy generators apply for accreditation. Once verified, the plant becomes an accredited TREC generator and is registered in the TREC system register as such (DME, 2007).

Issuing and verification of TREC: After the green energy is produced and verified by the Issuing Body, the generator receives certificates for a specified quantity of renewable energy. Each certificate is uniquely identifiable, certifies the quantity and type of green electricity produced and contains standard information such as a unique certificate number, generation plant identity, time of issue, type of technology and date of expiry (GreenX Energy, 2008). The TRECs are created as electronic records in the TREC register and are credited to the register account of the generator (Mitchell and Anderson, 2000).

Trading and transferring of TRECS: The whereabouts of the electronic certificate is registered, tracked and monitored from the point of issue, through trades and exchanges to redemption (Mitchell and Anderson, 2000). This ongoing registration of the certificate will guard against double counting. Trading can occur until such time as the TREC is redeemed, exported, or expired (DME, 2007).

Withdrawal from circulation: A TREC is said to have been redeemed once it has been consumed in fulfillment of a renewable energy obligation. At this stage, the TREC is withdrawn from circulation. (Mitchell and Anderson, 2000)

\subsection{Elements of a TREC system}

The essential elements of a TREC system can be broadly categorized as, firstly, a system of governance, secondly, the rules by which certificates are traded and, thirdly, the overall institutional context within which the system is developed (DME, 2007). These three elements are briefly discussed below. For a more detailed exposition, the reader is referred to DME (2007).

The system of governance refers to mandatory versus voluntary policy contexts. In a mandatory policy environment, the legislated TREC system provides verification and monitoring of compliance with government legislated obligations. Conversely, voluntary TREC systems are established - with or without government involvement - by market participants. (DME, 2007)

A TREC system requires clearly defined system rules of operation. The Renewable Energy Certificate System (RECS) is currently the only international TREC issuing and trading system. RECS is an umbrella organisation which governs an association of independent Issuing Bodies called the Association of Issuing Bodies (AIB). The Principles and Rules of Operation (PRO), previously known as the Basic Commitment, was developed by the AIB and sets out the common international standards that all AIB members must subscribe to (AIB, 2008). The PRO 'is one of the cornerstones of TRECs in the world and could be defined as the basis of TRECs in Europe, it is linked to all TRECs worldwide and has now also been adopted by 
the USA to form the basis of their TRECs verification, monitoring, tracking and control system' (DME, 2007: 52). The PRO prescribes a minimum set of criteria for the creation, issue, transfer and redemption of certificates to which all RECS Issuing Bodies must subscribe (DME, 2007).

Two groups of institutions are relevant when considering the institutional set-up of a TREC system, namely, assorted market participants and the TREC Issuing Body: TREC market participants include renewable energy generators (TREC producers), TREC traders and TREC consumers. The Issuing Body, as discussed above, is the organisation responsible for the implementation of the rules and procedures of the TREC system. The Issuing Body is responsible for accreditation of renewable energy generators via a physical device audit; registration of accredited renewable energy generators; issuing of TRECs in market participant accounts in a central database; operating the TREC register and administering market participant accounts; transferring TRECs; facilitating the international transfer of TRECs where compatible; redeeming certificates; and ongoing monitoring, development and evaluation of the TREC system. (DME, 2007)

The institutional setup of the Issuing Body must be sufficiently entrenched so as to allow for legal recourse in the event that dispute resolution is required and/or in oversight of its operational activities. For the TREC system to be both credible and reliable, it is important that the Issuing Body acts independently from the market participants and must not have a vested interest in the TREC market. (DME, 2007)

\subsection{Green certificate trading in South Africa}

The TREC market in South Africa at present is voluntary and in its infancy. The South African National Tradable Renewable Energy Certificate Team (SANTRECT) was formed by the Department of Minerals and Energy in March 2008 (DME, 2008). SANTRECT is charged with the responsibility of facilitating and coordinating the establishment of the South African TREC Issuing Body (SATIB). SATIB, which is in the process of formation, will be the governance authority for the renewable industry, and will be responsible for registering, issuing, transferring and redeeming green certificates. SATIB will be based on the European AIB (GreenX Energy, 2008).

SANTRECT is intending on registering the Issuing Body by March 2009 (DME, 2008). Currently, the registration of renewable energy production devices is undertaken by Nano Energy - which has been operating as the Interim TREC Issuing Body since 2005 as part of the physical green power voluntary market pilot project and the emerging renewable energy certificate voluntary trading initiative. Agreements have been put in place for the operation of an interim central registration database by Amatola Green Power and GreenX Energy. Renewable energy device audits and registrations have been taking place since May 2005 - with six devices registered at September 2007 (Nano Energy, 2007).

\subsection{Motivation for a national TREC system}

TRECs can be used to track and verify green energy supply. Importantly, as TRECs can be used in both a voluntary or mandatory policy environment, the national TREC system will bridge the transition to a possible future mandatory TREC system and provide a mechanism with which to monitor compliance with future renewable energy obligations (DME, 2007).

The purchase of green attributes separate from the underlying physical electricity avoids the complexities and barriers that are associated with the physical trade of power in a monopoly environment. As such, a TREC system will allow for the proliferation of the renewable energy industry while these regulatory issues are resolved and developed (DME, 2007). Importantly, the verification of green power provides a credible platform from which individuals and organisations can demonstrate a commitment to environmentally sustainable purchases and consumption. A TREC system will enable market participants to transform this commitment into tangible initiatives and projects via auditable financial transactions (GreenX Energy). As 
this green certificate market grows, there is increasingly a need for coordination among parties issuing, trading and selling certificates so as to uphold the integrity of the TREC market, build consumer confidence and prevent double counting and fraudulent claims (DME, 2007).

TRECs allow the mandatory share of renewable electricity to be achieved more cost-effectively, as those for whom it is cheaper to switch to renewables can exceed the target and sell to those for whom it is relatively expensive to switch.

\section{International implementation of renewable energy support mechanisms}

The section provides an overview of the policy instruments used in Europe, the United States and Australia. Experiences from the international implementation of these policy instruments will inform our own recommendations for the development of a national TREC system.

\subsection{Europe}

\subsubsection{EU-15 member states}

Table 2 provides an overview of the main policies instruments used to support renewable electricity in EU-15 member states. Figure 1 indicates the evolution of the main support instruments in the EU-15 for the period 1997-2005. As evident from the figure, only eight countries did not have a major policy shift in this period (Haas et al, 2007a). Quota regulation in conjunction with tradable green certificates has recently replaced existing policy instruments in Belgium, Italy, Sweden and the UK. Tender schemes are not used as the dominating policy instrument in any EU-25 member state. It is evident that investment incentives are used by various countries as supplementary instruments.

Table 2: Overview of the main policies for renewable electricity in EU-15 member states Source: Ragwitz et al (2006)

\begin{tabular}{ll}
\hline \multicolumn{1}{c}{ Country } & \multicolumn{1}{c}{ Main electricity support scheme } \\
\hline Austria & Feed-in tariffs combined with regional investment incentives \\
Belgium & $\begin{array}{l}\text { Quota obligation system combined with TGC and minimum prices for renewable } \\
\text { electricity }\end{array}$ \\
Denmark & Feed-in tariffs \\
Finland & Energy tax exemption combined with investment incentives \\
France & Feed-in tariffs \\
Germany & Feed-in tariffs \\
Greece & Feed-in tariffs combined with investment incentives \\
Ireland & Tendering scheme (to be replace by a feed-in tariff scheme) \\
Italy & Quota obligation system combined with TGC \\
Luxembourg & Feed-in tariffs \\
Netherlands & Feed-in tariffs \\
Portugal & Feed-in tariffs combined with investment incentives \\
Spain & Feed-in tariffs \\
Sweden & Quota obligation system combined with TGC \\
UK & Quota obligation system combined with TGC \\
\hline
\end{tabular}




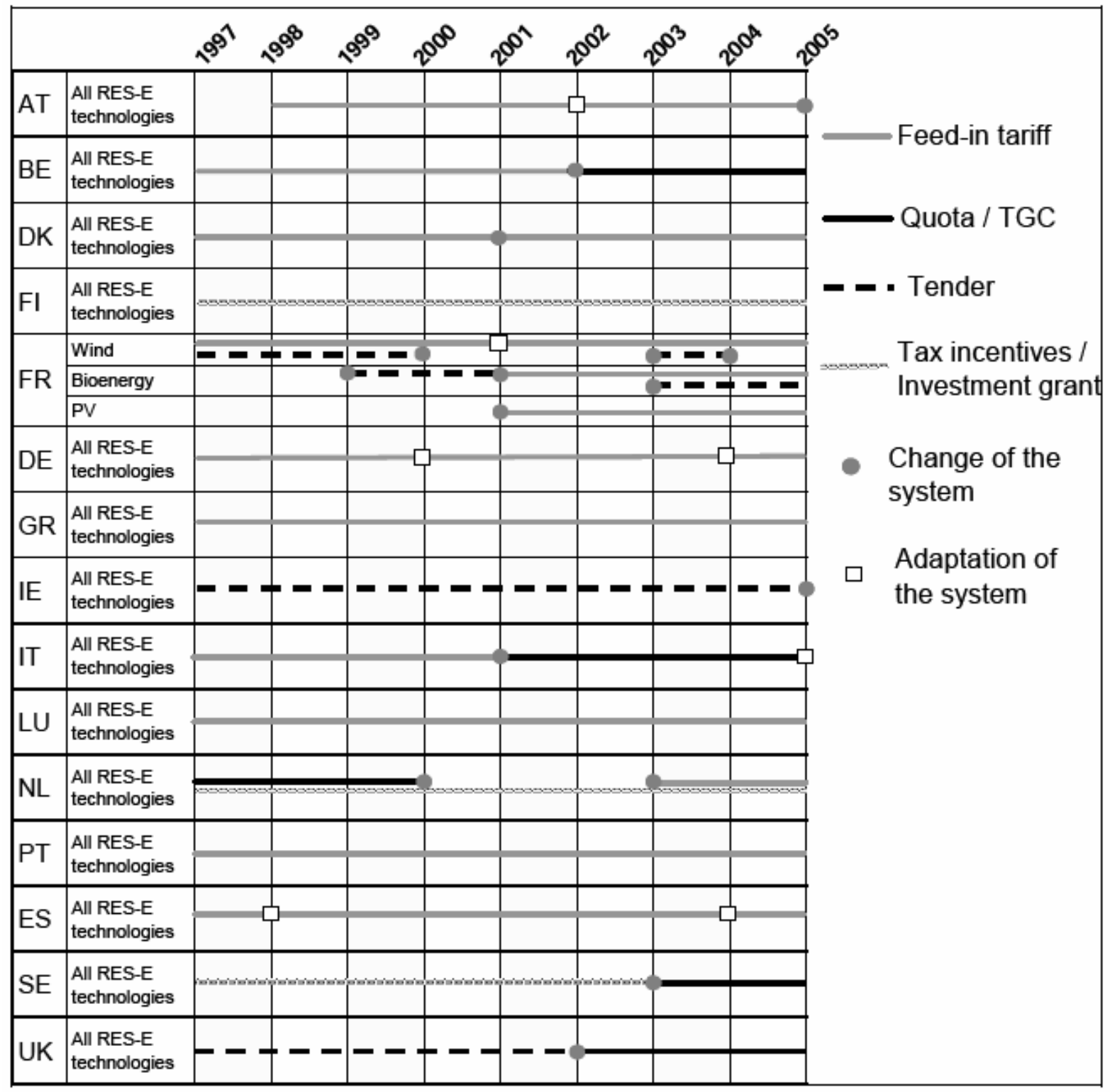

Figure 1: Evolution of the main renewable energy policy support scheme in EU-15 member states Source: Haas, Held, Resch, Ragwitz, Faber and Huber (2007a)

\subsubsection{The Renewable Energy Certificate System}

RECS is a international, voluntary TREC issuing and trading system operating in Europe with over 200 members in over 24 European countries (RECS, 2008). The system was created to stimulate global renewable energy development, advocate the usage of a standard certificate as evidence of the production of renewable energy, and provide a methodology which facilitates renewable energy trade (RECS, 2008). As has been previously mentioned, RECS is an umbrella organisation which governs the AIB - an organisation of individual TREC issuers (DME, 2007). The reader is referred to Section 3 for a brief discussion of the PRO: a framework developed by the AIB which sets out the mandatory standards to which all AIB members must subscribe.

\subsection{United States}

The Renewables Portfolio Standard (RPS) system aims to maintain or increase renewable energy contribution to electricity supply. ${ }^{8}$ RPS typically imposes a percentage renewable energy

8 It is important to note that RPS designs vary substantially across states. 
obligation on retail electricity suppliers. Most RPS policies are legislated. Renewable energy purchase obligations vary significantly among states from $2 \%-30 \%$ of retail sales. Currently, 25 states and Washington DC (Wiser and Barbose, 2008) have mandatory RPS obligations while four additional states have voluntary renewable energy standards. The amount of nationwide load covered by existing mandatory RPS programmes (including those not fully implemented as yet) is roughly $46 \%$ (Wiser and Barbose, 2008). Most RPS programmes incorporate the use of tradable renewable energy certificates (RECs) to increase flexibility, reduce compliance costs and facilitate compliance tracking. It is recognized that the application of RECs has contributed significantly towards the achievement of RPS targets, with the overall level of RPS compliance in 2006 estimated at around 94\% (Wiser and Barbose, 2008; Wiser et al, 2007).

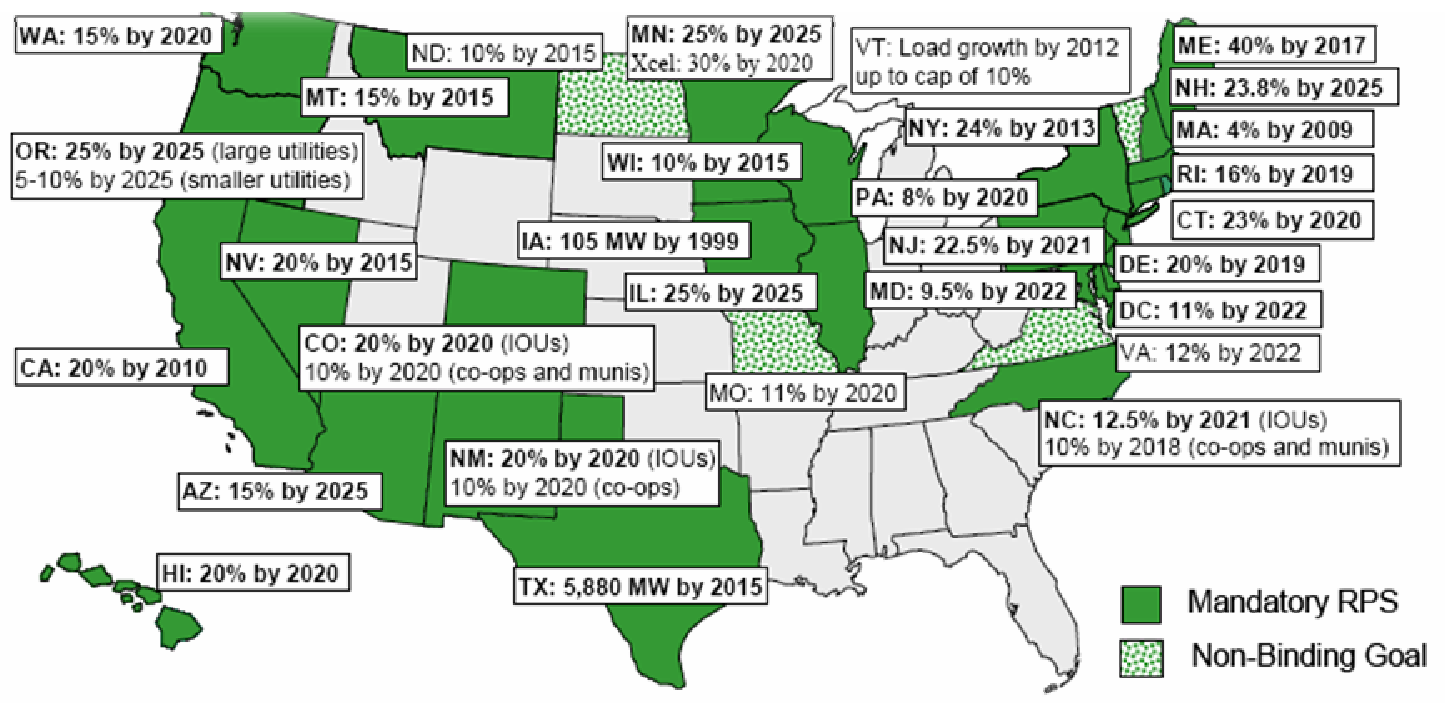

Figure 2: Existing state RPS policies and non-binding renewable energy goals Source: Renewables Portfolio Standards in the United States (April 2008)

\subsection{Australia}

The Australian Government introduced a Mandatory Renewable Energy Target (MRET) scheme in 2001 as part of a broader government response to climate change. The MRET scheme aims to increase the generation of electricity from renewable sources and reduce greenhouse gas emissions. The Renewable Energy (Electricity) Act of 2000 mandates the generation of an additional $9500 \mathrm{GWh}$ of renewable energy per year by 2010-2020. MRET operates by imposing a binding obligation to support renewable electricity generation on large wholesaler purchasers of electricity, for example, an electricity retailer buying wholesale electricity to meet retail sale obligations. The MRET is backed by a TREC system. If a liable party does not discharge their liability by surrendering TRECs, a Renewable Energy Shortfall Charge (penalty) of \$40 per TREC applies (Australian Government, 2008; Linden et al, 2005).

In 2007, under the national renewable energy target (RET) scheme, the Australian Government committed to ensuring that at least 20 per cent of Australia's electricity supply (approximately $60000 \mathrm{GWh}$ ) comes from renewable energy sources by 2020. Accordingly, the MRET will likely increase to $45000 \mathrm{GWh}$ to ensure that - together with the approximately $15000 \mathrm{GWh}$ of existing renewable capacity - Australia reaches the 20 per cent target by 2020 . Ultimately the national MRET and existing state-based targets will be brought into a single national scheme (COAG Working Group on Climate Change and Water, 2008).

The Department of Minerals and Energy (2007: 45) notes that by establishing MRET as a mandatory scheme: 
backed up by legislation and regulation - including monitoring using a TREC-based system and penalties for non-compliance - an effective and transparent implementation has been achieved.... The experience with the scheme confirms ... that by ensuring a solid 'paper trail' available through an internet based publicly accessible registry, monitoring and evaluation is significantly facilitated, and data quality and accuracy greatly strengthened.

\section{Basic design issues and concepts: lessons from the international experience; framework for a national TGC scheme}

In this section we indicate the basic design requirements for a TREC system and discuss some additional design elements that have emerged from the international experience.

Renewable electricity should be accredited to foster consumer confidence in green electricity, particularly in the case of voluntary TREC systems. In addition, the principle that there is equivalence between TRECs (standardisation), regardless of their means of production, is fundamental to the entire trading system. The accreditation and standardization body does not have to be linked to the government (as in the case of RECS). In addition, the national system should be in accordance with any international system so that international trade in certificates is a possibility. ${ }^{9}$ (Mitchell and Anderson, 2000)

The time aspects of TREC systems are important given that they can have a significant impact on the purchasing behaviour of market participants and thus on the price of green certificates. For example, a fixed annual obligation date might induce a rush to meet obligation targets as the deadline approached. This rush could result in inflated prices and increased market volatility. In a bid to build confidence in renewable energy markets and encourage a steady rate of renewable energy deployment, the design of the TREC system must aim to reduce the likelihood of TREC price hikes. Price hikes and associated market volatility are more likely to occur the longer the time horizon between redemption dates and the shorter the redemption period. While more frequent redemption dates are likely to have a smoothing effect in this regard, this benefit must be considered against the possibility of higher transaction costs. (Mitchell and Anderson, 2000)

In a bid to reduce the likelihood of price hikes, the following design options can be considered (Mitchell and Anderson, 2000):

- Banking: Where market participants can store surplus certificates (produced or procured) in the current redemption period for use in future redemption periods;

- Borrowing: Where actors with a shortfall of TRECs are able to reduce their target in the current redemption period by adding to their target in future redemption periods. This is usually considered to be unacceptable given that it shifts the risk away from the obligatee;

- Rolling redemption periods: Where market participants are able to meet their target over a prolonged period. If participants can meet their target over a five year period, their total TRECs target would be five times the size of an annual target, but they will be accorded flexibility in how they meet it. For example, years with low wind levels can be offset by years with higher wind levels. Such a system would require rolling deadlines

9 The possibility of international trade in certificates is an important feature of the TREC approach. The possibility for international trade implies that renewable technologies will be developed in those countries with the greatest production potentials and where renewable electricity can be produced at least cost. Countries with a surplus of TRECs in relation to national quotas can export certificates to those countries experiencing a shortage. As such, international trade can ensure that national renewable electricity targets are reached in the most cost-efficient way (Morthorst, 2001). 
and annual intermediate targets to prevent a large price hike at the end of the five year period; and

- TREC expiry dates: TRECs can be designed with an expiry date to ensure that they are used within a certain time period after their production. A short TREC lifetime encourages rapid deployment while an infinite TREC lifetime can be used to reassure the market.

In this context, Vogstad (2005) notes that TREC prices will be volatile and subject to weather fluctuations if flexible mechanisms such as borrowing and banking are not implemented.

The enforcement of penalties in the case of non-compliance must be guaranteed for the system to operate optimally; in addition, in order to incentivise market actors to fulfill their quota obligation, the penalty for non-compliance should be significantly higher than the expected market price for green certificates (Ragwitz et al, 2006). In the case of a TREC with no price cap, the penalty can be constructed as a flexible cost such as TREC $+\mathrm{X}$, where $\mathrm{X}$ is the penalty over and above the TREC market price. The penalty, also known as the buy out price, can be diverted to obligatees who have met their obligation (reducing their costs and encouraging compliance) (Anderson and Mitchell, 2000).

Based on extensive stakeholder consultation, Ragwitz et al (2006: 20) conclude that a long-term and stable policy environment - irrespective of the instrument utilised - is the single most important issue for success in developing renewable electricity markets:

Whether it concerns a feed-in tariff based support system, quota obligation scheme or tax incentive, in order to be able to attract investors and project developers, in order to allow sufficient time for project planning, realisation and all necessary steps of the authorisation procedure a framework with long term stability is highly desirable'.

A long-term framework is a necessary condition for the cost-effective promotion of renewable electricity generation. As such, long term renewable energy targets - such as setting renewable electricity targets for the year 2020 - can be important in creating a stable investment environment (Ragwitz et al, 2006),

The application of technology specific support can reduce transfer costs for society by increasing renewable energy deployment as less mature technologies receive a stimulus now becoming available to a larger extent in the future. A feed-in tariff is able to do this more easily than a uniform TREC system with no additional support. With respect to a feed-in tariff scheme, differentiation between renewable technologies can be easily implemented as the price level per technology can be set directly. As such, when considering the TREC framework, alternatives are available for the provision of technology specific support: combine a quota obligation/TREC system with other policy instruments such as investment grants or tax incentives $;{ }^{10}$ value a MWh of renewable electricity from different technologies differently where a MWh generated from a less mature or less cost efficient technology are translated into a green certificate with a value higher than one MWh (Ragwitz et al, 2006).

The risk assessment of investors with respect to a specific policy instrument affects the transfer costs for consumers, given that it is consumers who ultimately pay for the associated investor risk. The risk assessment of potential investors is influenced by the stability and type of the support scheme. Specifically, risk is positively correlated with investor uncertainty in terms of the sale of renewable electricity. Risk is lower in the context of a feed-in tariff scheme where both the magnitude and duration of support is known. Conversely, a high-risk premium exists under a TREC scenario as the income from the sale of TRECS is uncertain. Risks can be

10 This approach can be problematic when the TREC system is implemented internationally. In this case the TREC price is determined at the international level while the additional technology specific support is set at the national level. As such, countries that provide less additional support benefit from the international TREC price (Ragwitz et al, 2006). 
decreased, however, by the implementation of a guaranteed price floor for TRECs or the allowance of banking and borrowing of green certificates (Raqwitz et al, 2006).

Haas et al (2007) show that the level of support - expressed in terms of green certificate prices - in Belgium, Italy, and the UK is significantly higher than renewable energy generation costs. The reason for the higher support level, while partly due to immature TGC markets, is due to 'the non-technology-specific application of the currently applied TGC-systems as well as in [sic] a higher risk premium requested by investors' (Hass et al 2007: 2835)'. This indicates the importance of taking cognisance of the factors discussed above when determining the framework of a national TREC scheme.

A single policy instrument is typically not sufficient to develop the full gambit of renewable energy sources available in a particular country. The majority of renewable investments are the product of a combination of renewable energy support measures as opposed to one single policy instrument. In addition to feed-in tariffs and quota obligations combined with TGCs, which are the principle support schemes in Europe, various fiscal incentives, target setting, a long term framework and a stable policy environment have culminated in a stable investment climate for selected technologies in European markets (Ragwitz et al, 2006).

The 2007 DME feasibility report recommended the adoption of the Principles and Rules of Operation of the Association of Issuing Bodies

to provide a simple, clear, practical, and able to be readily implemented, administratively efficient method of operation and rules for South Africa... These rules provide a clear definition of eligible TREC renewable energy resources and technologies and the handling of each of these. As a tried and tested system, the PRO is manageable yet robust, reducing the likelihood of error or fraud. It is complementary to and compatible with existing policy, the legal and regulatory framework, and sustainable with minimum external financial requirements beyond the initial start-up years prior to sufficient market volume. Furthermore, as the basis for many other international TREC systems, it is compatible with and provides potential for co-operation with other prominent TREC systems. It specifies the rights and duties of market players and the tasks that need to be assigned to various bodies. The rules include verification requirements and procedures for the resolution of disputes. The PRO presents a clear definition of the content of the certificate and ensures that the benefits of renewable energy production are not double counted or sold several times. (DME, 2007: 13)

\section{Comparison of feed-in tariff and quota obligation combined with TGCs: lessons from international experience}

The following findings are drawn from a detailed analysis by Ragwitz et al (2006) of support schemes in EU-25 and EU-10 member states. The reader is referred to the source for more information.

\subsection{Feed-in tariffs}

- Feed-in tariffs have proved successful in triggering significant dissemination in renewable electricity technologies in all countries in which they have been implemented.

- A feed-in tariff is effective, flexible and fast in terms of renewable electricity deployment, it is easy to install and has minimal administration costs.

- The instrument easily facilitates the provision of technology specific support which helps to reduce transfer costs for consumers. 
- A feed-in tariff does not promote competition between investors. As such, it does not lead to reductions in electricity costs. This can be circumvented to some extent by guaranteeing a long tariff duration, which will result in efficiency gains.

- Feed-in tariffs are economically efficient if the tariff rates decline over time in line with the expected learning rate or a stepped feed-in tariff is applied.

- As feed-in tariffs are effective at relatively low producer profits, they provide deployment of renewable electricity at lowest costs for consumers, (Haas et al, 2007; Ragwitz et al, 2006)

\subsection{Quota obligations based on tradable green certificates}

- The instrument encourages competition among renewable electricity generators given that the market is sufficiently large;

- A quota obligation scheme in conjunction with tradable certificates results in minimal total renewable electricity costs but not minimal costs for consumers. This is because a higher risk premium is associated with a TGC scheme and a TGC system cannot reduce producer surplus. The implication is that such that a TGC scheme is cost efficient in terms of installed renewable electricity capacity but not in terms of costs borne by the consumer;

- In contrast to a feed-in tariff scheme, a significant advantage of this system is that the target will be exactly reached - with the provision of enough incentives such as penalties for non compliance (Ragwitz et al, 2006).

\section{Interaction between emissions trading and renewable energy promotion}

There is a significant distinction between schemes allowing for the trading of emission rights such as the Kyoto Protocol and schemes that develop a framework for the trade of renewable energy (or 'green') certificates. In emission trading schemes (ETSs), the tradable item is an entitlement to release a certain quantity of greenhouse gas emissions into the atmosphere. Conversely, with regard to a scheme that allows for or mandates trade in 'green' certificates, governments impose an obligation that a minimum share of the electricity generated or supplied to the retail consumer is derived from renewable energy sources (Jensen and Skytte, 2003).

Despite this distinction, the explicit goal of reducing carbon dioxide emissions creates a link between policies that promote renewable energy sources and other mitigation strategies like emissions trading. A TREC system might well act as a complement to an ETS. As ETS are technologically neutral, they do not support a specific technology but rather provide incentives for firms to use low-cost abatement technologies. Conversely, renewable energy promotion schemes directly support the proliferation of renewable energy technologies. Renewable energy technologies are typically high-cost emission mitigation alternatives and ETS provides a positive albeit limited incentive to their deployment. If the sole policy objective is carbon dioxide emissions reductions, the coexistence of ETS and renewable energy promotion schemes is arguably not recommended given that renewable energy generation is the more expensive option in the mitigation of greenhouse gas emissions. However, the additional socioeconomic and environmental benefits which accrue from renewable energy deployment do provide a justification for the coexistence of both instruments. In addition, the establishment of an ETS with a green certificate system can stimulate the generation of energy from renewable energy sources and create a shift towards renewable energy consumption (Gonzalez, 2007).

ETSs and renewable support schemes ultimately fulfill the same objective, namely the reduction of greenhouse gases. However, given that both policy instruments are directed at the same market segments, their interaction could lead to synergies as well as conflicts. Abrell and Weight (2008) quantitatively assess the interaction between an ETS and a tradable green 
certificate system using a static open economy computable general equilibrium (CGE) model. ${ }^{11}$ In addition to a business-as usual approach which replicates the 2004 German economy, three different scenarios are modeled: Firstly, an obligation for a 20 percent reduction in emissions from the electricity sector and energy intensive industries, secondly, the aforementioned 20 percent reduction target and a 20 percent renewable electricity quota using tradable green certificates and, thirdly, the aforementioned 20 percent reduction target and a 20 percent renewable electricity quota using feed-in tariffs.

In the first scenario of a 20 percent reduction in emissions, the carbon permit price is $3.43 € / t$ $\mathrm{CO}_{2}$. The electricity price increases by two percent amid an increase in the cost of generation: compared to a BAU approach (no regulation), emission regulation ultimately increases the marginal cost of fossil fuel based generation which results in higher electricity prices. In response to the higher electricity price, electricity demand and supply decreases by one percent and 1.6 percent, respectively. Both scenarios, in which a renewable electricity quota is imposed, are roughly identical. In both scenarios, the carbon permit price is reduced to zero, electricity prices rise by one percent, electricity demand falls by 0.72 percent and electricity supply falls by roughly one percent. Both renewable policies lead to a marginally higher welfare loss than the pure emission reduction scenario as 'electricity producers deviate from their cost minimizing generation portfolio' (Abrell and Weigt, 2008: 11).There is a welfare loss of 0.0019 percent in the first scenario, as compared to 0.0209 percent and 0.0213 percent in the second and third renewable energy scenarios, respectively.

Important conclusions can be drawn from this analysis. Firstly, renewable energy support instruments lead to a decrease in carbon prices (and ultimately in the electricity price) as the increased share of renewable energy decreases the demand for carbon permits. The extreme result of a zero carbon permit price, as described above, occurred because the renewable electricity quota led to an excess supply of carbon permits. The significant implication for policy design is that carbon regulation becomes unnecessary if renewable electricity targets are set too high (Abrell and Weigt, 2008).

In addition, the imposition of a renewable electricity quota in addition to an emission trading scheme results in additional welfare losses to society. The welfare loss is larger in the case of a feed-in tariff scheme. As such, the additional renewable electricity support instrument must be justified. The authors cite the learning effects associated with renewable energy technologies as the standard justification (Abrell and Weigt, 2008).

\section{References}

Abell, J., and H. Weigt. 2008. The interaction of emissions trading and renewable energy promotion. Economics of Global Warming WP-EGW-05, Dresden University of Technology.

Association of Issuing Bodies. 2008. The Principles and Rules of Operation. Available online at: www.aib-net.org/portal/page/portal/AIB_HOME/AIB_ASS/EECS/PRO.

Australian Government. 2008. Mandatory Renewable Energy Target Overview. Office of the Renewable Energy Regulator, available online at www.orer.gov.au/publications/pubs/mret-overview-feb08.pdf.

Boots, M. 2003. Green certificates and carbon trading in the Netherlands. Energy Policy, 31: 43-50.

Climate Analysis Indicators Tool CAIT. 2009: Version 6.0., Washington, DC: World Resources Institute, accesses January 2009, available online at http://cait.wri.org/.

COAG Working Group on Climate Change and Water. 2008. Design Options for the Expanded National Renewable Energy Target Scheme. Renewable Electricity Markets Team, Department of Climate Change.

Department of Environmental Affairs and Tourism. 2008. Investigation: Obstacles and Barriers to Renewable Energy in South Africa, available online at:

11 'The model is based on the German input-output table of the year $2004 \ldots$ which identifies 71 industries and commodities. Furthermore, the German statistical office provides energy flows and emissions of the German economy... which are used to construct physical energy flows corresponding to value flows of the input-output table and carbon emissions' (Abrell and Weigt: 8). 
Department of Minerals and Energy. 2003. White Paper on Renewable Energy, available online at www.dme.gov.za/pdfs/energy/renewable/white_paper_renewable_energy.pdf.

Department of Minerals and Energy. 2007. Tradable Renewable Energy Certificates System Feasibility Study Final Report, Report No. DME/CE/001/260307.

Department of Minerals and Energy .2008: www.dme.gov.za/energy/renew_TRECS.stm.

Electricity Regulation Act. 2004. Available online at www.info.gov.za/gazette/acts/2006/a4-06.pdf.

Fakir, S., and D. Nicol. 2008. Investigation: Obstacles and Barriers to Renewable Energy in South Africa, Centre for Renewable and Sustainable Energy Studies, University of Stellenbosch, study prepared for the National Environment Advisory Forum.

GreenX Energy 2008. Tradable Renewable Energy Certificates. Available online at www. steadfastgreening.co.za/docs/FAQs_about_TRECs.pdf.

Gonzalez, P. 2007. The interaction between emission trading and renewable electricity support scheme, Mitig Adapt Strat Global Change 12: 1363-1390.

Haas, R., Eichhammer, W., Huber, C., Langniss, O., Lorenzoni, A., Madlener, R., Menanteau, P., Morthorst, P., Martins, A., Oniszk, A., Schleich, J., Smith, A., Vass, Z., and A. Verbruggen. 2004. How to promote renewable energy systems successfully and effectively. Energy Policy 32: 833 - 839.

Haas, R., Resch, G., Faber, T., and C. Huber. 2007: Lessons learned from recent promotion strategies for electricity from renewables. Proceedings of ISES Solar World Congress 2007: Solar Energy and Human Settlement.

Haas, R., Held, A., Resch, G., Ragwitz, M., Faber, T., and C. Huber. 2007a. Lessons learned from recent promotion strategies for electricity from renewables in EU countries, available online at www.risoe.dk/rispubl/reports/ris-r-1608_21-31.pdf.

Held, A., and M. Ragwitz. 2006. Effectiveness and efficiency of present RES-E support policies in EU Member States, OPTRES Dissemination Workshop, Copenhagen.

Jensen, S., and K. Skytte. 2003. Simultaneous attainment of energy goals by means of green certificates and emission permits, Energy Policy 31: 63-71.

Linden, N., Uyterlinde, M., Vrolijk, C., Nilsson, L., Khan, J., Astrand, K., Ericsson, K. and R. Wiser. 2005: Review of international experience with renewable energy obligation support mechanisms, Energy Research Centre of the Netherlands, IT Power, UK, Lawrence Berkeley National Laboratory, USA, and University of Lund, Sweden, LBNL-57666.

Marquard, A., Merven, B., and E. Tyler. 2008: Costing a 2020 target of $15 \%$ renewable electricity for South Africa, Energy Research Centre, University of Cape Town.

Mitchell, C. and T. Anderson. 2000. The implications of tradable green certificates for the UK, ETSU Project No. TGCK/BD?00218.

Morthorst, P.E. 2001. Interactions of a tradable green certificate market with a tradable permits market. Energy Policy 29: 345-353.

Nano Energy. 2007. Correspondence between Jason Schaffler, Managing Director of Nano Energy, and South African National TREC Team.

RECS. 2008. RECS International Association, available online at www.recs.org/information.asp.

Ragwitz, M., Held, A., Sensfuss, F., Huber, C., Resch, G., Faber, T., Haas, R., Coenraads, R., Voogt, M., Morotz, A., Jensen, S., Morthorst, P., Konstantinaviciute, I., and B. Heyder. 2006: OPTRES: Assessment of optimisation of renewable support schemes in the European electricity market, Interim report of the project.

Renewable Energy Foundation. 2008. UK renewables subsidies: A simple description and commentary. available online at: www.ref.org.uk

UNFCCC. 1992: United Nations Framework Convention on Climate Change, New York, United Nations, available at_http://unfccc.int/resource/docs/convkp/conveng.pdf.

UNFCCC 1997. Kyoto Protocol, available at: http://unfecc.int, last accessed January 2009.

Vogstad, K. 2005. Combining system dynamics and experimental economics to analyse the design of Tradable Green Certificates, $38^{\text {th }}$ International Conference on System Sciences.

Winkler, H. 2005. Renewable energy policy in South Africa: policy options for renewable electricity, Energy Policy 33: 27-38.

Wiser, R. and G. Barbose. 2008. Renewables portfolio standards in the United States: A status report with data through 2007. Environmental Energy Technologies Division, Lawrence Berkeley National Laboratory, LBNL-154E. 
Wiser, R., Namovicz, C., Gielecki, M., and R. Smith. 2007: Renewables portfolio standards: A factual introduction to experience from the United States. Environmental Energy Technologies Division, Lawrence Berkeley National Laboratory, LBNL-62569. 